\title{
The Mother or the Fetus? $11 \beta$-Hydroxysteroid Dehydrogenase Type 2 Null Mice Provide Evidence for Direct Fetal Programming of Behavior by Endogenous Glucocorticoids
}

\author{
Megan C. Holmes, ${ }^{1}$ Christian T. Abrahamsen, ${ }^{1}$ Karen L. French, ${ }^{1}$ Janice M. Paterson, ${ }^{2}$ John J. Mullins, ${ }^{2}$ and \\ Jonathan R. Seckl ${ }^{1}$ \\ ${ }^{1}$ Endocrinology Unit and ${ }^{2}$ Molecular Physiology Laboratory, Centre for Cardiovascular Disease, Queen's Medical Research Institute, University of \\ Edinburgh, Edinburgh EH16 4TJ, United Kingdom
}

\begin{abstract}
Low birth weight associates with increased susceptibility to adult cardiometabolic and affective disorders spawning the notion of fetal "programming." Prenatal exposure to excess glucocorticoids may be causal. In support, maternal stress or treatment during pregnancy with dexamethasone (which crosses the placenta) or inhibitors of fetoplacental $11 \beta$-hydroxysteroid dehydrogenase type $2(11 \beta$-HSD2), the physiological "barrier" to maternal glucocorticoids, reduces birth weight and programs permanent offspring hypertension, hyperglycemia, and anxiety behaviors. It remains uncertain whether such effects are mediated indirectly via altered maternal function or directly on the fetus and its placenta. To dissect this critical issue, we mated $11 \beta$-HSD2 ${ }^{+/-}$mice such that each pregnant female produces $+/+,+/-$, and $-/-$ offspring and compared them with offspring of homozygous wild-type and $-/-$ matings. We show that $11 \beta-$ $\mathrm{HSD} 2{ }^{-/-}$offspring of either $+/-$or $-/-$mothers have lower birth weight and exhibit greater anxiety than $11 \beta-\mathrm{HSD} 2{ }^{+/+}$littermates. This provides clear evidence for the key role of fetoplacental 11 $\beta$-HSD2 in prenatal glucocorticoid programming.
\end{abstract}

Key words: anxiety; hypothalamic-pituitary-adrenal axis; glucocorticoids; programming; behavior; $11 \beta$-hydroxysteroid dehydrogenase

\section{Introduction}

An adverse prenatal environment "programs" lifelong susceptibility to adult disorders such as hypertension, diabetes/insulin resistance, heart disease, as well as depression and schizophrenia (Barker, 2004; Eriksson et al., 2004; Huizink et al., 2004). Studies in several model species have shown that exposure of a pregnant female to repeated stress or to the synthetic glucocorticoid dexamethasone, which crosses the placenta, reduces offspring birth weight and causes lifelong hypertension, hyperglycemia, hypothalamic-pituitary-adrenal (HPA) axis hyperactivity, and anxiety-related behaviors in adult life (Seckl, 2004). Intriguingly, prenatal exposure of humans to dexamethasone is subsequently associated with elevated blood pressure (Doyle et al., 2003), hyperinsulinemia (Dalziel et al., 2005), and altered emotionality in later life (Trautman et al., 1995).

Normally, the fetus is protected, at least in large part, from the much higher levels of glucocorticoids (corticosterone in rats and mice, cortisol in other mammals) in the maternal blood by placental $11 \beta$-hydroxysteroid dehydrogenase type $2(11 \beta$-HSD2). This catalyzes the rapid inactivation of cortisol and corticosterone to their

Received 0ct. 19, 2005; revised Feb. 22, 2006; accepted Feb. 24, 2006.

This work was supported by a Wellcome Trust project grant (M.C.H.) and program grant (J.R.S., J.J.M.) and a Medical Research Council studentship (C.T.A.). We thank William Mungall for his technical support with animal care and maintenance.

Correspondence should be addressed to Dr. Megan C. Holmes, Endocrinology Unit, Centre for Cardiovascular Disease, Queen's Medical Research Institute, 47 Little France Crescent, Edinburgh EH16 4TJ, UK. E-mail: Megan.Holmes@ed.ac.uk.

DOI:10.1523/JNEUROSCI.4464-05.2006

Copyright $\odot 2006$ Society for Neuroscience $\quad$ 0270-6474/06/263840-05\$15.00/0 inert 11-keto forms (cortisone, 11-dehydrocorticosterone). In adult life, $11 \beta$-HSD2 is highly expressed in the kidney, where it excludes active glucocorticoids from mineralocorticoid receptors (MRs) in vivo, thus allowing aldosterone selective access. Congenital deficiency of $11 \beta$-HSD2 or its inhibition by liquorice derivatives allows activation of MRs by glucocorticoids causing hypernatremia, hypertension, and hypokalemia; the syndrome of apparent mineralocorticoid excess (AME) (Stewart et al., 1988; White et al., 1997).

The placenta and the fetal brain highly express $11 \beta$-HSD2 until the end of midgestation (Brown et al., 1996; Waddell et al., 1996). It has been proposed that relative deficiency of placental and/or fetal $11 \beta$-HSD2, by allowing greater passage of maternal glucocorticoids to fetal tissues, might be the physiological parallel to the effects of dexamethasone, a poor substrate for $11 \beta$-HSD2, which crosses the placenta. In support of this notion, activity of placental $11 \beta$-HSD2 correlates with birth weight (Lindsay et al., 1996; Welberg et al., 2000; Murphy et al., 2002). Moreover, in rats, maternal treatment during pregnancy with dexamethasone or the nonselective $11 \beta$-HSD inhibitor carbenoxolone reduces birth weight and produces permanent hypertension, hyperglycemia, and behavior reminiscent of anxiety (Lindsay et al., 1996; Welberg et al., 2000, 2001). However, because all prenatal models used to date involve maternal manipulations, the locus of effect is unknown. This is crucial because postnatally maternal behavioral factors are major critical influences determining offspring brain programming (Liu et al., 2000; Weaver et al., 2004).

In this paper, we test the hypothesis that $11 \beta$-HSD2 expres- 
sion in the placenta and fetus protects the fetus from overexposure to maternal glucocorticoids in the mouse, resulting in programming of the offspring. The phenotype of $11 \beta$-HSD $2^{-1-}$ mice has been reported (Kotelevtsev et al., 1999); however, the targeted $11 \beta$-HSD2 allele has now been backcrossed onto the C57BL/6J strain, which exhibits a much milder phenotype of systolic hypertension $(+8 \mathrm{mmHg})$ in young adult offspring (J. M. Paterson, M. A. Bailey, P. W. F. Hadoke, D. G. Brownstein, C. Bellamy, S. Fleming, J. R. Seckl, and J. J. Mullins, unpublished observations). We have now examined the effects of $11 \beta$-HSD2 nullizygosity on offspring's behavior and HPA activity.

\section{Materials and Methods}

Animals

For homozygous matings of $\mathrm{C} 57 \mathrm{BL} / 6 \mathrm{~J}$ or $11 \beta-\mathrm{HSD} 2^{-1-}$ congenic on C57BL/6J background, a male and female of the respective genotype were housed together in a breeding cage with bedding for nest building.

In other experiments, male and female $11 \beta$-HSD2 ${ }^{+/-}$mice congenic on the $\mathrm{C} 57 \mathrm{BL} / 6 \mathrm{~J}$ background were housed in pairs in a breeding cage as above. Offspring consisting of $11 \beta$-HSD $2+/+,+/-$, and $-/-$ were compared within the same litter. Genotyping was performed by PCR using these primers: B2Forw, AACGGGCTCCAAGTTGAGTC; B2Rev, GCTTCAGGCGAGGAGAACAGAGGTCACG; NEORev, CGCTTCCTCGTGCTTTACGGTATCGCCGCTCC.

Animals were given standard chow and water ad libitum, lights were on from 7 A.M. to 7 P.M., and all studies were performed to the highest standards of humane animal care under the aegis of the United Kingdom Animals (Scientific Procedures) Act, 1986. All pups were weighed on the day of birth and/or at the time of killing.

\section{Behavioral testing}

Adult male mice were tested in two types of behavioral tasks in a random order. Immediately before the testing, mice were brought into the testing room in their home cage, and testing started immediately with no acclimatization period. Mice were group housed, and no more than two mice from each cage were tested. No differences were seen between mouse 1 or 2 from a cage or whether mice were tested in an apparatus first or second. Three days were allowed between tests on each apparatus. Tests were videotaped or captured by a computer tracking program (Limelight; Actimetrics, Wilmette, IL) to allow full analysis.

Open field test. Mice were placed in an open field (OF) box $(60 \times 60$ $\mathrm{cm}$ ) marked off into 25 equal squares. The outer row of squares adjacent to the walls of the field are considered less anxiogenic than the inner squares. For a 5 min period, the number of crossings, time, and distance (movement of all four legs into a new square) into each square was noted. Total movement in the maze reflects general activity and the relative movement in the inner zone is correlated to the anxiety state of the mouse.

Elevated plus maze. Mice were placed on the central region of the elevated plus maze (EPM) (two intercrossing arms of white plastic, $\sim 90$ $\mathrm{cm}$ long and $5 \mathrm{~cm}$ wide; two opposite arms are enclosed and two are open, and the maze is elevated $\sim 1 \mathrm{~m}$ from the floor), and movement around the maze for $5 \mathrm{~min}$ was assessed. The open arms are considered a more anxiogenic environment, and so crossing, movement, and time spent on these arms compared with total movement is a reflection of anxiety state.

\section{HPA axis activity}

Male mice as adults ( $>2$ months of age) were tested for HPA axis function. Basal blood samples were taken from a tail nick at 8 A.M., the nadir of the corticosterone diurnal rhythm, and peak stress samples were taken from trunk blood after $10 \mathrm{~min}$ in a Perspex restraint tube. At time of killing, brains were collected and rapidly frozen on dry ice and stored at $-80^{\circ} \mathrm{C}$ until processed further for gene expression. Adrenals were also collected in some animals, which were cleaned of fat and weighed.

In situ hybridization for glucocorticoid receptor and MR steadystate $m R N A$ expression

Coronal cryostat sections $(10 \mu \mathrm{m})$ at the level of the hippocampus were mounted onto gelatin- and poly-L-lysine-coated slides and stored at $-80^{\circ} \mathrm{C}$. In situ hybridization studies were performed according to Harris et al. (2001). Plasmids containing fragments of cDNA for rat glucocorticoid receptor (GR) (1691-2364 bp) and MR (2769-3282 bp) were used as templates to transcribe radiolabeled sense and antisense riboprobes using ${ }^{35} \mathrm{~S}$-UTP (Amersham Biosciences, Little Chalfont, UK). Following the hybridization protocol, the slides were exposed to autoradiographic film for 1 week at room temperature. Five to 10 readings were taken from each region of each tissue section (three sections per mouse). Sections were dipped in photographic emulsion (NTB2; Kodak, Rochester, NY) and stored at $4^{\circ} \mathrm{C}$ before development and counterstaining with pyronin $(1 \%, w / v)$. Grain counting was performed using an MCID system (Imaging Research, St. Catharines, Ontario, Canada).

\section{Analysis of plasma corticosterone}

Trunk blood was collected into EDTA-coated Microvette tubes (Sarstedt, Numbrecht, Germany) and centrifuged, and then plasma was stored at $-20^{\circ} \mathrm{C}$ until corticosterone determination by radioimmunoassay as described previously (Holmes et al., 1997).

\section{Statistical analysis}

All data are expressed as group means \pm SEM. Statistical significance between groups was determined by one- or two-way ANOVA followed by Dunnett's post hoc test, or Student's $t$ test, as appropriate.

\section{Results}

Birth weight and growth are altered in $11 \beta$-HSD $2^{-1-}$ mice

There was no difference in the size of the litters produced by C57BL/6J matings or $11 \beta$-HSD2 ${ }^{-1-}$ matings (C57BL/6J, $7.2 \pm$ $0.4, n=21 ; 11 \beta$-HSD $\left.{ }^{-1-}, 6.4 \pm 0.6, n=28\right)$. However, the weight of pups born from $11 \beta$-HSD $2^{-1-}$ male and female pairs was significantly less than C57BL/6J controls (C57BL/6J, $1.33 \pm$ $0.019 \mathrm{~g}, n=32 ; 11 \beta$-HSD2 $\left.{ }^{-/-}, 1.21 \pm 0.023 \mathrm{~g}, n=34 ; p<0.01\right)$. $11 \beta$-HSD $2^{-1-}$ mice remained smaller throughout life (e.g., 9 months of age, C57BL/6J, $38.83 \pm 1.52 \mathrm{~g}$, and $11 \beta-\mathrm{HSD}^{-\prime-}$, $30.08 \pm 0.78 \mathrm{~g} ; n=10$ ); this might be attributable to either altered programmed growth trajectories and/or their AME phenotype.

To determine whether the differences between the birth weights and subsequent growth trajectories of $11 \beta$-HSD $2^{+/+}$ and $11 \beta$-HSD2 $2^{-1-}$ mice were attributable to loss of $11 \beta$-HSD2 in the mother (i.e., AME-induced alterations in maternal physiology, health, and/or behavior including the "AME" uterine environment) or attributable to lack of $11 \beta$-HSD2 in fetoplacental tissues, heterozygous $\left(11 \beta-\mathrm{HSD}^{+/-}\right)$male and female pairs of mice were mated, and the various genotypes of offspring within the same heterozygous mother compared. Strikingly, birth weight followed offspring genotype, with wild-type the heaviest offspring, heterozygotes intermediate, and $11 \beta$-HSD $2^{-1-}$ offspring the lightest at birth (Fig. 1). Thus, birth weight reduction with deficiency of $11 \beta$-HSD2 reflects loss of the enzyme in the fetoplacental compartment and does not require maternal AME. Postnatal catch-up growth, well recognized in human low birth weight cohorts, and several animal models, was observed in the $11 \beta$-HSD $2^{+/-}$and $11 \beta$-HSD2 ${ }^{-/-}$offspring such that, at postnatal day 7 (P7) and P15, there were no significant differences in body weights between the genotypes (supplemental Table 1, available at www.jneurosci.org as supplemental material), which continued into adulthood. Thus, persisting weight deficits in the offspring of $11 \beta$-HSD2 ${ }^{-1-}$ matings reflect aspects of maternal biology rather than lack of the enzyme in the fetoplacental compartment or offspring AME per se.

\section{Anxiety behavior is observed in $11 \beta-\mathrm{HSD}^{-/-}$mice}

Administration of $11 \beta$-HSD inhibitors or nonsubstrate glucocorticoids such as dexamethasone in pregnant rats programs 
Weight (g)

1.5

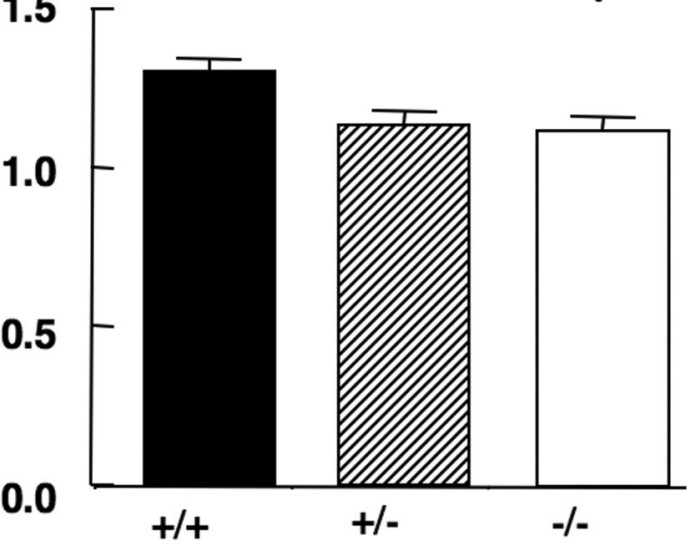

6
12 a)

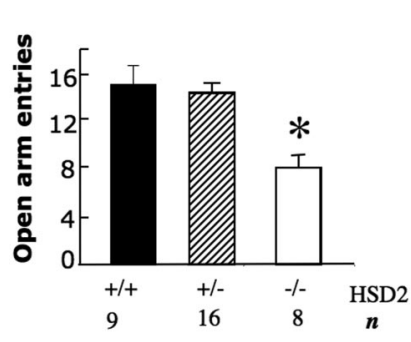

b)

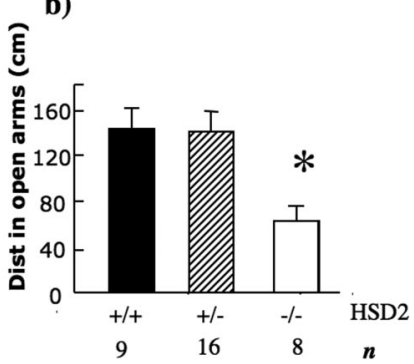

Figure 3. $11 \beta-\mathrm{HSD} 2^{-/-}$mice from heterozygous matings show increased anxiety in the elevated plus maze test. Open arm entries ( $\boldsymbol{a}$ ) and distance traveled in open arms $(\boldsymbol{b})$ in $11 \beta$ $\mathrm{HSD}^{+/+}$(filled columns), $11 \beta$-HSD2 ${ }^{+/-}$(striped columns), and HSD ${ }^{-/-}$(open columns) littermates are shown. The columns represent means \pm SEM. ${ }^{*} p<0.05$ compared with $11 \beta$ $\mathrm{HSD}^{+/+}$control.

HSD2

$n$

Figure 1. Birth weights of $11 \beta-\mathrm{HSD2}^{+/+}$(filled columns), $11 \beta$-HSD2 ${ }^{+/-}$(striped columns), and $11 \beta$-HSD2 ${ }^{-1-}$ (open columns) offspring from $11 \beta-\mathrm{HSD2}^{+/-}$matings. The columns represent means \pm SEM. ${ }^{*} p<0.05$ compared with $11 \beta$-HSD2 ${ }^{+/+}$controls.

\section{\%Open:Total}

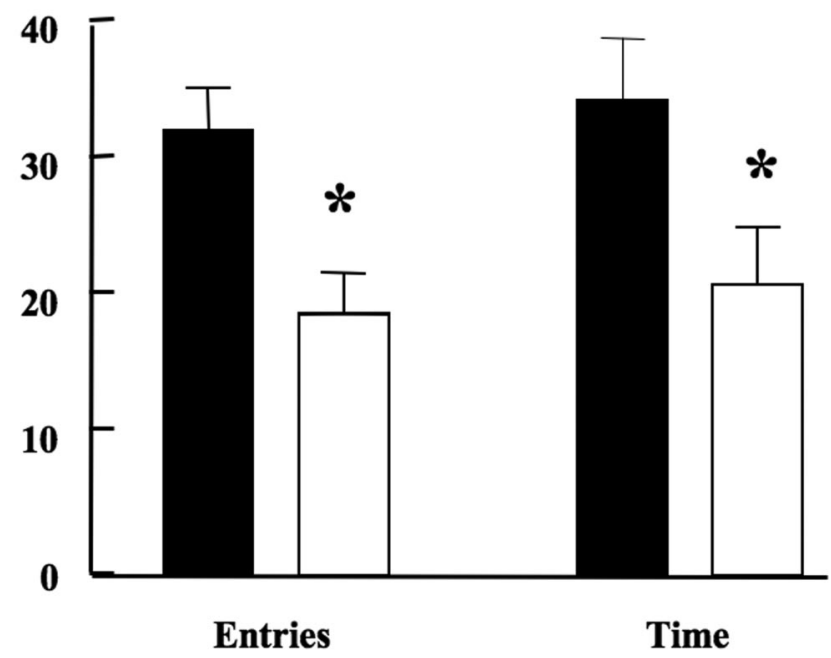

Figure 2. $11 \beta-\mathrm{HSD}^{-/-}$mice from homozygous matings show increased anxiety in elevated plus maze test. $11 \beta$-HSD2 ${ }^{-/-}$mice (open columns) show decreased number of entries and time spent in open arms of EPM compared with $11 \beta-\mathrm{HSD2}{ }^{+/+}$mice (filled columns). The columns represent means \pm SEM. $n=26 .{ }^{*} p<0.05$ compared with $11 \beta-H S D 2{ }^{+/+}$control.

anxiety behavior in the offspring. In the EPM anxiety test, $11 \beta$ $\mathrm{HSD}^{-1-}$ mice made significantly fewer entries into the more anxiogenic open arms and spent less time there, indicating elevated anxiety (Fig. 2). However, total activity on the maze was similar between genotypes (total entries: C57BL/6J, $15.5 \pm 1.3$, $n=26 ; 11 \beta$-HSD2 $\left.{ }^{-1-}, 15.7 \pm 1.15, n=26\right)$. To confirm this finding, $11 \beta$-HSD2 ${ }^{-/-}$and wild-type C57BL/6J mice were further examined for anxiety-like behavior in the OF test. $11 \beta$ HSD $2^{-1-}$ mice exhibited significantly fewer crossings into the anxiogenic inner area (expressed as a percentage of total crossings throughout the maze to control for locomotion) compared with wild-type (C57BL/6J: $31.1 \pm 1.6 \%, n=26 ; 11 \beta$-HSD2 ${ }^{-/-}$: $23.7 \pm 2.3 \%, n=34 ; p<0.05)$, implying greater anxiety-related behavior. There was no significant difference in total crossings between the 2 genotypes (C57BL/6J: $188.7 \pm 12.8, n=26$; $11 \beta$ HSD2 $\left.{ }^{-1-}: 212 \pm 10.5, n=26\right)$. Maternal care is important in determining offspring behavior. Therefore we tested anxiety behavior in $11 \beta$-HSD2 $+/+,+/-$, and $-/-$ littermates from heterogygous matings. $11 \beta$-HSD $2^{-/-}$offspring showed decreased open arm entries and decreased distance traveled in the open arms compared with their wild-type littermates from the same mother (Fig. $3 a, b$ ), paralleling the anxiety phenotype of $11 \beta$ $\mathrm{HSD}^{-1-}$ mice from $11 \beta-\mathrm{HSD} 2^{-1-}$ mothers. However, performance in the open field was similar between genotypes (percentage of inner crossings: C57BL/6J, $17 \pm 2.3 \%, n=9$; $11 \beta$-HSD2 ${ }^{+/-}, 20.2 \pm 1.8 \%, n=15 ; 11 \beta$-HSD2 ${ }^{-/-}, 16.4 \pm$ $3.2 \%, n=7$; total activity/crossings: C57BL/6J, $156.6 \pm 17.9$; $11 \beta$-HSD2 ${ }^{+/-}, 199.1 \pm 11.8 ; 11 \beta$-HSD $\left.2^{-/-}, 218.4 \pm 21.1\right)$, suggesting a maternal component may also be contributing to a more robust anxiogenic phenotype in $11 \beta$-HSD $2^{-1-}$ mice from a $11 \beta$-HSD $2^{-/-}$mother.

HPA axis activity is unchanged in $11 \beta$-HSD $2^{-/-}$mice As offspring from rats and other species prenatally exposed to dexamethasone, carbenoxolone, or stress have permanently altered HPA axis activity, we investigated the HPA function in adult male $11 \beta$-HSD2 $2^{-1-}$ mice. Adrenal weights from $11 \beta$ HSD $2^{-1-}$ mice were significantly smaller than controls (ratio of adrenal weight/body weight $\left(\times 10^{-5}\right)$ : wild type, $5.2 \pm 0.5 ; 11 \beta$ $\left.\mathrm{HSD}^{-/-}, 4.1 \pm 0.3 ; n=10 ; p<0.05\right)$, suggesting a compensatory downward resetting of HPA function in the absence of catabolism of active corticosterone by $11 \beta$-HSD2. Adrenal hypotrophy was also observed in $11 \beta$-HSD $2^{-1-}$ mice derived from heterozygous matings $\left(11 \beta\right.$-HSD $2^{+/+}, 1.87 \pm 0.09 \mathrm{mg}, n=$ $18 ; 11 \beta$-HSD2 ${ }^{+/-}, 1.9 \pm 0.05 \mathrm{mg}, n=32 ; 11 \beta$-HSD $2^{-1-}, 1.59 \pm$ $0.07 \mathrm{mg}, n=16$ ), confirming the phenotype is dependent on the $11 \beta$-HSD2 genotype of the fetus, rather than the mother. Despite this, in adult offspring from $11 \beta$-HSD $2^{-/-}$matings, both basal and peak stress (10 min restraint) plasma corticosterone levels were maintained at control C57BL/6J levels (supplemental Fig. 1, available at www.jneurosci.org as supplemental material). Furthermore, MR and GR mRNA levels within the hippocampus as well as GR mRNA in the paraventricular nucleus of the hypothalamus, targets altered with prenatal glucocorticoid programming and sensitive to tissue corticosterone levels (Holmes et al., 1995; Levitt et al., 1996; Welberg et al., 2001), were not significantly different between control and $11 \beta$-HSD2 ${ }^{-1-}$ mice (supplemental Table 2, available at www.jneurosci.org as supplemental material). Hence, regulation of the HPA axis appears to be unchanged/reset by the absence of $11 \beta$-HSD2. Moreover, basal and 
poststress plasma corticosterone levels in all genotypes from heterozygous matings were similar (supplemental Fig. 1, available at www.jneurosci.org as supplemental material).

\section{Discussion}

The key issue addressed in this research is to define the target for prenatal programming by glucocorticoids: the mother or the fetoplacental unit? The results suggest that $11 \beta$-HSD2 deficiency, and hence exposure to excess glucocorticoids, reduces birth weight and programs the fetal brain. Furthermore, loss of fetoplacental enzyme is sufficient to cause much of this without indirect maternal effects; however, a component of maternal component exaggerates the effects.

\section{Lack of $11 \beta$-HSD2 activity results in low birth weight and altered growth}

$11 \beta$-HSD $2^{-1-}$ matings produced lighter offspring than congenic C57BL/6J controls, implicating the enzyme in the control of fetal growth and birth weight. This finding recapitulates results with $11 \beta$-HSD inhibitors in the pregnant rat (Lindsay et al., 1996; Welberg et al., 2000). However, $11 \beta$-HSD2 is expressed in the maternal kidney and plays a key role in maternal fluid and electrolyte balance and hence blood pressure control (Kotelevtsev et al., 1999). Moreover, carbenoxolone also inhibits $11 \beta$-HSD1, an oxidoreductase that locally regenerates glucocorticoids and is expressed in liver and adipose tissue and plays a key role in metabolic control (Morton et al., 2004). 11 $\beta$-HSD1 is also expressed in the uterus and decidua, so dissecting the locus of effect of carbenoxolone is complex. However, because birth weight also followed fetal $11 \beta$-HSD2 genotype within the same (heterozygous) mother, the results here demonstrate that reduced birth weight is an effect of allowing excessive glucocorticoid action on the fetus and/or placental trophoblast rather than any effects mediated via changes in maternal blood pressure or metabolism. It is intriguing that there was a significant gene dosage effect with heterozygous offspring intermediate in birth weight. This supports the hypothesis that variation in placental $11 \beta$-HSD2 activity, by allowing excessive fetal exposure to maternal glucocorticoids, links the maternal environment with fetal growth and development. Until this work, this notion has been dependent on correlational analyses only. Whether exogenous agents such as dexamethasone, stress, and carbenoxolone only act on birth weight via fetoplacental actions alone or also have maternal effects remains uncertain, but the data here show that fetoplacental effects are sufficient.

In contrast, postnatal growth trajectories differed between the offspring of $11 \beta$-HSD $2^{-/-}$matings and $11 \beta$-HSD $2^{-/-}$offspring of heterozygous matings. $11 \beta$-HSD $2^{-/-}$offspring of $11 \beta$ HSD $2^{-1-}$ mothers did not exhibit catch-up growth postnatally and remained 20-25\% lighter than congenic C57BL/6J controls into midlife, whereas genetically identical $11 \beta$-HSD $2^{-1-}$ offspring of $11 \beta$-HSD $2^{+/-}$mothers showed full catch-up growth by weaning and had the same adult weight as wild-type littermates. This cannot easily be ascribed to the postnatal AME syndrome, which is mild on this genetic background and is anticipated to be similar in the two situations. It is conceivable that the growth retardation was more marked in $11 \beta$-HSD $2^{-1-}$ offspring of $11 \beta$ $\mathrm{HSD}^{-1-}$ than $11 \beta-\mathrm{HSD} 2^{+/-}$mothers because of a greater growth retardation signal in offspring of the more biologically abnormal mothers, although this was not marked by a greater reduction in birth weight. More plausibly, the discordance may reflect differences in maternal care and/or nutrient provision postnatally. In support of this contention, lactating female $11 \beta$ -
HSD $2^{-1-}$ mice alone have appreciable mortality (Paterson et al., 2005), presumed to reflect exacerbation of already abnormal maternal fluid and electrolyte handling at a time of challenge. Whatever the maternal mechanism involved, the lack of early catch-up growth in $11 \beta$-HSD $2^{-1-}$ offspring of $11 \beta$-HSD $2^{-1-}$ mothers, but not of $11 \beta$-HSD $2^{+/-}$mothers, persists after weaning, implying that the combination of prenatal and postnatal growth retardation cannot be readily reversed. This is reminiscent of studies with nutritional restriction prenatally and/or postnatally in which catch-up growth after prenatal restriction is attenuated after additional postnatal constraint, perhaps because of permanent changes in hypothalamic appetitive circuitry (Desai et al., 2005).

$11 \beta$-HSD2-null mice show programming of anxiety behavior $11 \beta$-HSD2 is highly expressed in the adult kidney, where it potently influences blood pressure, making assessment of any fetal programming of cardiovascular characteristics unfeasible in $11 \beta$ HSD $2^{-1-}$ models. In contrast, the adult mouse forebrain has no $11 \beta$-HSD2 (limited expression in rat forebrain is not observed in the mouse). Conversely, plentiful $11 \beta$-HSD2 is present in the fetal CNS until the end of midgestation with the subsequent patterns of loss of $11 \beta$-HSD2 paralleling terminal differentiation of particular regions (Brown et al., 1996; Diaz et al., 1998). Thus, any CNS programming likely reflects developmental effects. Anxiety behavior is found in rodent models of prenatal programming by dexamethasone administration (Welberg et al., 2001), prenatal stress (Welberg et al., 2001; Maccari et al., 2003), or inhibition of $11 \beta$-HSD by carbenoxolone (Welberg et al., 2000); but all involve manipulation of the mother, and therefore maternal physiology and behavior may contribute to fetal abnormalities. Here, we show increased anxiety-related behaviors seen in $11 \beta$-HSD $2^{-/-}$offspring of $11 \beta$-HSD $2^{-/-}$and $11 \beta$-HSD $2^{+/-}$ mothers, suggesting it is predominantly attributable to fetal effects rather than alterations of maternal physiology or behavior. Interestingly, anxiety phenotypes were not observed in $11 \beta$ HSD $2^{+/-}$heterozygote littermates, although these have an intermediate birth weight phenotype. It is unclear whether this reflects the insensitivity of the CNS to glucocorticoid programming of behavior or insensitivity of methods of assessment of affective function in mice.

However, whereas anxiety-related behavior in the EPM was similar in $11 \beta$-HSD $2^{-1-}$ offspring of either $11 \beta$-HSD $2^{-1-}$ or $11 \beta$-HSD2 ${ }^{+/-}$mothers, open field behavior was abnormal only in $11 \beta$-HSD $2^{-1-}$ offspring of $11 \beta$-HSD $2^{-1-}$ mothers. This implies that, as with postnatal growth, aspects of adult behavior are also influenced by maternal factors, perhaps an unsurprising finding but nonetheless important in the strictly genetically and endocrinologically confined contexts of the models used here. In this perspective, prenatal stress programs altered adult behavior, but effects are powerfully influenced by early postnatal environmental manipulations.

\section{Loss of $11 \beta$-HSD 2 activity has no effect on HPA axis activity}

In most model species, prenatal programming, including by glucocorticoids, carbenoxolone, or stress, induces lifelong alterations (typically increases) in HPA axis activity (Maccari et al., 1995; Weinstock, 1997; Welberg et al., 2000). Low birth weight human cohorts have increased HPA activity. However, $11 \beta$ $\mathrm{HSD}^{-1-}$ mice, whether from $11 \beta$-HSD $2^{-1-}$ mothers with AME or apparently healthy heterozygous $11 \beta$-HSD $2^{+/-}$mothers, had no alterations of HPA parameters. This seemingly surprising finding has several possible explanations. First, the mouse 
(as a species) may not be susceptible to programming of the HPA axis in general (unlikely) or the C57BL/6J strain may be unusually resistant to HPA axis hyperactivity (R. Carter, Paterson, and M. C. Holmes, unpublished observation). Second, the mild hypertension and electrolyte imbalance in adult C57BL/6J-11 $\beta$ HSD $2^{-1-}$ mice throughout life may serve to "reset" HPA axis activity, although how this might occur is moot. Third, the "normal" HPA function in $11 \beta$-HSD2 $2^{-/-}$mice might be considered surprising because the reduced clearance of corticosterone in $11 \beta$-HSD $2^{-1-}$ mice and thus the lower activity of the HPA axis needed to maintain circulating corticosterone levels (as evidenced by adrenal hypoplasia) is anticipated to attenuate HPA responses to stress. Perhaps fetal HPA axis programming is indeed seen in both models and is reflected by paradoxically normal HPA responses to stress when hypoactivity is expected. However, an important feature of the $11 \beta-\mathrm{HSD} 2^{-1-}$ mouse is that the behavioral effects of early life glucocorticoid overexposure are clearly independent of HPA axis hyperactivity, removing adult elevated glucocorticoids as being the primary cause of the anxiety phenotype.

\section{Summary}

In conclusion, we have shown that loss of $11 \beta$-HSD2 activity results in an early life exposure to high maternal glucocorticoids, resulting in low birth weight and a programmed behavioral phenotype of increased anxiety. At present, we cannot exclude the lifelong mild hypertension and electrolyte imbalance attributable to loss of kidney $11 \beta$-HSD2 activity having a role in altering behavior, nor can we determine for sure the relative importance of placental versus fetal brain $11 \beta$-HSD2 protection. These points will be addressed in future studies involving conditional knock-out of $11 \beta$-HSD2. This is the first model of programming that unequivocally demonstrates the importance of $11 \beta$-HSD2 in the fetus and placenta in a situation that rules out maternal pathophysiology and behavior as contributing factors.

\section{References}

Barker DJ (2004) The developmental origins of chronic adult disease. Acta Paediatr Suppl 93:26-33.

Brown RW, Diaz R, Robson AC, Kotolevtsev Y, Mullins JJ, Kaufman MH, Seckl JR (1996) The ontogeny of $11 \beta$-hydroxysteroid dehydrogenase type 2 and mineralocorticoid receptor gene expression reveal intricate control of glucocorticoid action in development. Endocrinology 137:794-797.

Dalziel SR, Walker NK, Parag V, Mantell C, Rea HH, Rodgers A, Harding JE (2005) Cardiovascular risk factors after antenatal exposure to betamethasone: 30-year follow-up of a randomised controlled trial. Lancet 365:1856-1862.

Desai M, Gayle D, Babu J, Ross MG (2005) Programmed obesity in intrauterine growth-restricted newborns: modulation by newborn nutrition. Am J Physiol 288:R91-R96.

Diaz R, Brown RW, Seckl JR (1998) Distinct ontogeny of glucocorticoid and mineralocorticoid receptor and $11 \beta$-hydroxysteroid dehydrogenase types I and II mRNAs in the fetal rat brain suggest a complex control of glucocorticoid actions. J Neurosci 18:2570-2580.

Doyle LW, Faber B, Callanan C, Morley R (2003) Blood pressure in late adolescence and very low birth weight. Pediatrics 111:252-257.

Eriksson M, Wallander MA, Krakau I, Wedel H, Svardsudd K (2004) The impact of birth weight on coronary heart disease morbidity and mortality in a birth cohort followed up for 85 years: a population-based study of men born in 1913. J Intern Med 256:472-481.

Harris HJ, Kotelevtsev Y, Mullins JJ, Seckl JR, Holmes MC (2001) Intracellular regeneration of glucocorticoids by $11 \beta$-hydroxysteroid dehydrogenase (11 $\beta$-HSD)-1 plays a key role in regulation of the hypothalamic- pituitary-adrenal axis: analysis of $11 \beta$-HSD-1-deficient mice. Endocrinology 142:114-120.

Holmes MC, Yau JL, French KL, Seckl JR (1995) The effect of adrenalectomy on 5-hydroxytryptamine and corticosteroid receptor subtype mRNA expression in rat hippocampus. Neuroscience 64:327-337.

Holmes MC, French KL, Seckl JR (1997) Dysregulation of diurnal rhythms of serotonin $5-\mathrm{HT}_{2 \mathrm{C}}$ and corticosteroid receptor gene expression in the hippocampus with food restriction and glucocorticoids. J Neurosci 17:4056-4065.

Huizink AC, Mulder EJ, Buitelaar JK (2004) Prenatal stress and risk for psychopathology: specific effects or induction of general susceptibility? Psychol Bull 130:115-142.

Kotelevtsev Y, Brown RW, Fleming S, Kenyon C, Edwards CRW, Seckl JR, Mullins JJ (1999) Hypertension in mice lacking $11 \beta$-hydroxysteroid dehydrogenase type 2. J Clin Invest 103:683-689.

Levitt NS, Lindsay RS, Holmes MC, Seckl JR (1996) Dexamethasone in the last week of pregnancy attenuates hippocampal glucocorticoid receptor gene expression and elevates blood pressure in the adult offspring in the rat. Neuroendocrinology 64:412-418.

Lindsay RS, Lindsay M, Edwards CRW, Seckl JR (1996) Inhibition of $11 \beta$ hydroxysteroid dehydrogenase in pregnant rats and the programming of blood pressure in the offspring. Hypertension 27:1200-1204.

Liu D, Diorio J, Day JC, Francis DD, Meaney MJ (2000) Maternal care, hippocampal synaptogenesis and cognitive development in rats. Nat Neurosci 3:799-806.

Maccari S, Piazza PV, Kabbaj M, Barbazanges A, Simon H, Le Moal M (1995) Adoption reverses the long-term impairment in glucocorticoid feedback induced by prenatal stress. J Neurosci 15:110-116.

Maccari S, Darnaudery M, Morley-Fletcher S, Zuena AR, Cinque C, Van Reeth O (2003) Prenatal stress and long-term consequences: implications of glucocorticoid hormones. Neurosci Biobehav Rev 27:119-127.

Morton NM, Paterson JM, Masuzaki H, Holmes MC, Staels B, Fievet C, Walker BR, Flier JS, Mullins JJ, Seckl JR (2004) Novel adipose tissuemediated resistance to diet-induced visceral obesity in $11 \beta$ hydroxysteroid dehydrogenase type 1-deficient mice. Diabetes 53:931-938.

Murphy VE, Zakar T, Smith R, Giles WB, Gibson PG, Clifton VL (2002) Reduced $11 \beta$-hydroxysteroid dehydrogenase type 2 activity is associated with decreased birth weight centile in pregnancies complicated by asthma. J Clin Endocrinol Metab 87:1660-1668.

Paterson JM, Seckl JR, Mullins JJ (2005) Genetic manipulation of $11 \beta$ hydroxysteroid dehydrogenases in mice. Am J Physiol 289:R642-R652.

Seckl JR (2004) Prenatal glucocorticoids and long-term programming. Eur J Endocrinol 151 [Suppl 3]:U49-U62.

Stewart PM, Corrie JET, Shackleton CHL, Edwards CRW (1988) Syndrome of apparent mineralocorticoid excess: a defect in the cortisol-cortisone shuttle. J Clin Invest 82:340-349.

Trautman PD, Meyer-Bahlburg HFL, Postelnek J, New MI (1995) Effects of early prenatal dexamethasone on the cognitive and behavioral development of young children: results of a pilot study. Psychoneuroendocrinology 20:439-449.

Waddell BJ, Benediktsson R, Seckl JR (1996) 11 $\beta$-Hydroxysteroid dehydrogenase type 2 in the rat corpus luteum: induction of mRNA expression and bioactivity coincident with luteal regression. Endocrinology 137:5386-5391.

Weaver IC, Cervoni N, Champagne FA, D’Alessio AC, Sharma S, Seckl JR, Dymov S, Szyf M, Meaney MJ (2004) Epigenetic programming by maternal behavior. Nat Neurosci 7:847-854.

Weinstock M (1997) Does prenatal stress impair coping and regulation of hypothalamic-pituitary-adrenal axis? Neurosci Biobehav Rev 21:1-10.

Welberg LA, Seckl JR, Holmes MC (2000) Inhibition of $11 \beta$-hydroxysteroid dehydrogenase, the foeto-placental barrier to maternal glucocorticoids, permanently programs amygdala GR mRNA expression and anxiety-like behaviour in the offspring. Eur J Neurosci 12:1047-1054.

Welberg LA, Seckl JR, Holmes MC (2001) Prenatal glucocorticoid programming of brain corticosteroid receptors and corticotrophin-releasing hormone: possible implications for behaviour. Neuroscience 104:71-79.

White PC, Mune T, Agarwal AK (1997) $11 \beta$-Hydroxysteroid dehydrogenase and the syndrome of apparent mineralocorticoid excess. Endocr Rev 18:135-156. 